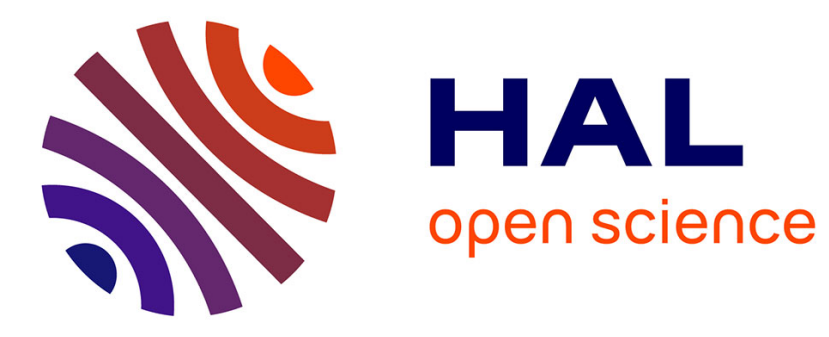

\title{
High-level Athletes' Motivation for Sport and Susceptibility to Doping: The Mediating Role of Eating Behaviours
}

Stéphanie Scoffier-Mériaux, Fabienne d'Arripe-Longueville, Tim Woodman, Vanessa Lentillon-Kaestner, Karine Corrion

\section{To cite this version:}

Stéphanie Scoffier-Mériaux, Fabienne d'Arripe-Longueville, Tim Woodman, Vanessa LentillonKaestner, Karine Corrion. High-level Athletes' Motivation for Sport and Susceptibility to Doping: The Mediating Role of Eating Behaviours. European Journal of Sport Science, In press. hal-02531858

\section{HAL Id: hal-02531858 \\ https://hal.univ-cotedazur.fr/hal-02531858}

Submitted on 6 Apr 2020

HAL is a multi-disciplinary open access archive for the deposit and dissemination of scientific research documents, whether they are published or not. The documents may come from teaching and research institutions in France or abroad, or from public or private research centers.
L'archive ouverte pluridisciplinaire HAL, est destinée au dépôt et à la diffusion de documents scientifiques de niveau recherche, publiés ou non, émanant des établissements d'enseignement et de recherche français ou étrangers, des laboratoires publics ou privés. 
2 High-level Athletes' Motivation for Sport and Susceptibility to

3 Doping: The Mediating Role of Eating Behaviours

4 Stéphanie Scoffier-Mériaux ${ }^{1 *}$, Fabienne d'Arripe-Longueville ${ }^{1}$, Tim

5 Woodman $^{2}$, Vanessa Lentillon-Kaestner ${ }^{3}$, and Karine Corrion ${ }^{1}$

6

7

$8 \quad{ }^{1}$ Université Côte d'Azur, LAMHESS EA6312, France

$9{ }^{2}$ University of Bangor, UK.

$10{ }^{3}$ University of Teacher Education, State of Vaud (HEP-VD), Switzerland 11 Address correspondence to: Stéphanie Scoffier-Mériaux

13 Université Côte d'Azur

14 Laboratory of Human Motricity Education Sport and Health (LAMHESS - EA 6312)

15 Faculty of Sport Sciences

16 261, route du Mercantour B.P. 3259

1706205 Nice Cedex 03, France

18 Phone: ++ 33492296529

19 Fax: ++ 33492296 537; E-mail: smeriaux@ unice.fr

20

21 Submitted: February 2019 
MOTIVATION, EATING BEHAVIOUR, AND DOPING

1 High-level Athletes' Motivation for Sport and Susceptibility to Doping: The Mediating

2 Role of Eating Behaviours

\section{Introduction}

4 The World Anti-Doping Agency Code (2015) defines doping as a violation of one or more

5 anti-doping rules as set forth in Article 2.1 through Article 2.8. Petróczi (2007) defined

6 doping as the use of prohibited means to enhance performance with the intention of gaining a

7 competitive advantage over the opponent. As doping behaviours are difficult to capture

8 directly, most studies have focused on attitudes towards doping (e.g., Petróczi \& Aidman,

92009 ) and the motivation or intention to do so, taking into account variables such as

10 susceptibility to doping and social appraisal (e.g., Barkoukis, Lazuras, Tsorbatzoudis, \&

11 Rodafinos, 2013). Self-determination theory (SDT) has been applied for the prediction of a

12 number of health-related behaviours (e.g., Hagger et al., 2014), including doping (see Chan et

13 al., 2018b, for a review) and eating behaviours (Hagger, Chatzisarantis, \& Harris, 2006).

14 However, no research to date has examined these processes together to determine whether

15 and how motivation, eating behaviours, and susceptibility to doping are related. The purpose

16 of the present study was therefore to gain deeper insight into the relationship between

17 motivation for sport and the susceptibility to doping within the SDT framework through the

18 potential mediating role of eating behaviour in this relationship. A deeper understanding of

19 the psychological processes that underlie doping will better equip coaches and other frontline

20 personnel to identify maladaptive behaviours.

\section{Sport motivation and susceptibility to doping}

According to SDT, there are two broad types of motivation: autonomous motivation

23 and controlled motivation (Ryan \& Deci, 2000, 2008). Autonomous motivation occurs when

24 an individual feels independently and freely engaged in a behaviour. It has been shown to

25 predict intended and actual effort (Deci \& Ryan, 1991) and includes intrinsic motivation and 
1 self-determined forms of extrinsic motivation (i.e., identified regulation and integrated

2 regulation). Controlled motivation includes external regulation and introjected regulation and

3 is not self-determined. In this case, individuals who feel under the pressure of external

4 constraints (e.g., rewards and demands from others) suffer negative cognitive, affective, and

5 behavioural consequences (Deci \& Ryan, 2000). Deci and Ryan (2000; Ryan \& Deci, 2008)

6 established a taxonomy of motivation along a continuum that covers the degrees of self-

7 determined behaviour from non-self-determined to self-determined.

Several studies have documented the associations between self-determined motivation

9 and doping behaviours in athletes (e.g., Chan et al., 2018a; Corrion et al., 2017; Hodge et al., 10 2013). For example, Hodge et al. (2013) revealed that autonomous motivation was negatively 11 associated with aspects of doping (i.e., attitudes towards drugs and drug-taking 12 susceptibility). Similarly, other studies (e.g., Barkoukis, Lazuras, Tsorbatzoudis, \&

13 Rodafinos, 2011; Chan et al., 2015) have shown that the intrinsically motivated athlete profile 14 is associated with a low propensity to doping. In their preliminary systematic review, Chan et 15 al. (2018b) indicated that self-determined motivation makes athletes more likely to endorse 16 sportspersonship orientations and consequently prevents them from engaging in unethical 17 behaviours such as the use of performance-enhancing substances. Self-determination theory 18 certainly appears to be a fruitful framework for examining the motivational regulation 19 processes that might underpin athletes' susceptibility to doping.

\section{Self-determination and eating behaviours}

21 Self-determination theory has been applied to predict a number of health-related 22 behaviours (e.g., Hagger et al., 2014), including eating behaviours (Hagger et al., 2006; Mata 23 et al., 2009). These authors have suggested that increased general self-determination or high 24 levels of autonomous motivation to exercise or diet facilitate improvements in eating self25 regulation and healthy body weight maintenance. A few studies have examined the 
MOTIVATION, EATING BEHAVIOUR, AND DOPING

1 association between self-determination and food regulation in everyday life (e.g., Kopp \&

2 Zimmer-Gembeck, 2011; Mask \& Blanchard, 2011). These studies have reported that acting

3 in a self-determined way protects against the harmful effects of the sociocultural pressure to

4 be thin and is negatively related to the adoption of a thin ideal. In other words, self-

5 determined individuals are less likely to develop unhealthy eating behaviours because they

6 better self-regulate their behaviour (e.g., eating in response to emotional arousal states such

7 as fear, anger or anxiety).

8 Eating behaviour and substance use

9

10

11

Previous research has shown that emotional eating behaviours may make people more sensitive to the immediate food environment (e.g., Cebolla, Barrada, van Strien, Olivier, \& Banos, 2014). A typical example of emotional eating is seeking immediate gratification from food in response to an emotional state, as when an individual who feels anxious engages in frequent compensatory and comforting eating (Frayn \& Knauper, 2018). This process has common ground with the propensity to doping, as doping is typically an emotionally driven response to allay fears of underperforming. As such, the person impulsively turns to the doping "solution" much like the emotional eater turns to food. Indeed, neuroticism and impulsivity (Garcia-Argibay, 2019) and low self-control (Kabiri, Shadmanfaat, \& Donner, 2019) have been shown to be significant predictors of doping. We ever know that the Dutch Eating Behaviour Questionnaire factors have also been related to eating disorders such as anorexia nervosa (e.g., Kiezebrink, Campbell, Mann, \& Blundell, 2009), bulimia nervosa and binge-eating disorder (e.g., van Strien, Engels, van Leeuwe, \& Snoek, 2005). In the sport domain, we hypothesise that the consumption of legal substances (e.g., nutritional supplement use) could be a pathway to doping in elite and amateur sports (e.g., Ntoumanis et al., 2014). Nutritional supplement use is associated with specific reasoning patterns in favour of doping, and this mechanism may explain why some of these users decide to engage in 
1 doping (Barkoukis et al., 2015). Furthermore, recent research based on clinical interviews

2 suggested that disordered eating in high-level athletes was associated with doping behaviour

3 (Rousselet et al., 2017), whereas knowledge on nutrition may be a protective factor against

4 doping (Kondric, Sekulic, Ujevic, Gabrilo, \& Zvan, 2013). Despite the strong theoretical and

5 empirical link between eating behaviours and doping, to date little is known about the

6 underlying psychological mechanism of this relationship.

$7 \quad$ The present study

8

\section{Method}

\section{Participants} susceptibility.

Although doping (e.g., Hodge et al., 2013) and eating behaviours (e.g., Hagger et al., 2006) have been studied independently within the SDT framework, no study has examined these variables concomitantly. Yet as we have seen, eating behaviours and doping share common conceptual and practical/emotional ground. In addition, the eating behaviours of athletes are less severe than doping, we propose that eating behaviours may be a pathway towards doping and may mediate the relationship between sport motivation and doping

In the present study, we used SDT as a heuristic framework for examining (i) motivational regulation processes in the relationship with doping susceptibility and (ii) the role of eating behaviours in this relationship. Specifically, we hypothesized that autonomously motivated athletes (i.e., high in intrinsic and identified motivation) would be more likely to regulate their eating behaviours and engage in healthy eating, and thus be less likely to dope. Conversely, we hypothesized that more extrinsically motivated athletes (i.e., high in introjected and external regulation) would be more likely to engage in unhealthy eating habits and thus be more likely to dope. The overarching hypothesis is that motivation is associated with the propensity to doping via eating behaviours (see Figure 1). 
2 ranging from 15 to 24 years $\left(M_{\text {age }}=21.40 ; S D=5.12\right)$. All were competing in sports in which

3 athletes were considered to be at risk of developing unhealthy eating behaviours and/or in

4 sports known for a high prevalence of doping (Alaranta et al., 2006; Sherman \& Thompson,

5 2009). The athletes were eligible to participate in the study if they met the following criteria:

6 (a) minimum age of 15 years, (b) more than 8 hours of physical training per week, and (c)

7 more than 5 years of sport experience. The sample of the present study comprised

8 participants engaged in team sports (i.e., rugby; $N=89$ ), endurance sports (i.e. triathlon,

9 running, cycling; $N=41$ ), and aesthetic sports (i.e., figure skating, gymnastics; $N=41$ ). All

10 participants competed at the national or international level and were in-season.

\section{Procedure}

12 The ethics committee of the local University approved the protocol. Written consent 13 was obtained from the training centres and the participants (or their parents in the case of 14 minors). Athletes completed the questionnaires at the beginning or the end of a training 15 session, depending on their availability. They completed the questionnaires under 16 standardized conditions (i.e., in isolation, paper and pencil) in no more than 20 minutes.

17 Participants were informed beforehand that they were not obliged to respond and that 18 anonymity would be maintained. We also informed them that this was not a test (i.e., that 19 there were no right or wrong answers) and that all responses would remain strictly 20 confidential and would be used for research purposes only.

\section{Measures}

22 The survey included demographic questions (gender, age, sport, and skill level) and 23 measures of motivation for sport, eating behaviours, and susceptibility for doping use. To 24 assess the validity of the motivation for sport and eating behaviour measures, confirmatory 25 factor analyses (CFA) were performed using bootstrapped maximum likelihood estimation 
1 with the AMOS 7.0 program. The CFA of each subscale was examined with relative fit

2 indices as recommended by $\mathrm{Hu}$ and Bentler (1999). Therefore, the comparative fit index

3 (CFI), the Tucker-Lewis index (TLI), and the root mean square error of approximation

4 (RMSEA) were used to evaluate model fit. Modification indices were used to flag fixed

5 parameters in the model that would make a significant change in the goodness-of-fit chi-

6 square value if freed, and the likelihood-ratio test based on the goodness-of-fit chi-square was

7 used to identify misspecifications in the constrained models from the invariance analyses

8 relative to the baseline model. In this study, and for each measure, Cronbach's alphas were

9 considered marginally acceptable from .60, according to the recommendations of Briggs-

10 Gowan and Carter (1998).

11 Motivation for sport. The Behavioural Regulation in Exercise Questionnaire

12 (BREQ) assesses behavioural regulation according to the SDT framework in the exercise

13 domain. The scale has been validated in many languages and presents good psychometric

14 properties. We used a version of the BREQ that was adapted to sport (BREQ-2; Markland \&

15 Tobin, 2004). This scale consists of 19 items on a 5-point Likert-type scale with responses

16 that range from 1 (Strongly disagree) to 6 (Strongly agree). Items are grouped into five

17 subscales (i.e., amotivation, external regulation, introjected regulation, identified regulation,

18 and intrinsic regulation), which represent the types of behavioural regulation underlying the

19 motivational continuum of SDT, although it should be noted that integrated regulation is not

20 included (Deci \& Ryan, 1985). The BREQ-2 has been shown to have good psychometric

21 properties (e.g., Markland \& Tobin, 2004). In the present study, the term "exercise" was

22 replaced by "sport" in all items. The CFA provided support for a five-factor model, indicating

23 that the model was acceptable $\left(\chi^{2}=312.17 ; N=199 ; \mathrm{df}=264 ; \mathrm{CFI}=.95\right.$; TLI $=.93$; RMSEA

$24=.068 ;$ RMSEA 90\% CI $=.054 / .080)$. The subscale amotivation was not considered in

25 further analyses because the participants were competitive athletes and amotivation is the 
MOTIVATION, EATING BEHAVIOUR, AND DOPING

1 state in which an individual lacks the intention to act (Deci \& Ryan, 2000). All Cronbach

2 alpha values are presented in Table 1.

Eating behaviours. The Dutch Eating Behaviour Questionnaire (DEBQ; Van Strien, 2002) was developed to measure eating styles. The 33-item DEBQ, validated in French by

5 Bailly, Maitre, Amanda, Hervé, and Alaphilippe (2012), was used to measure a global index

6 of eating behaviour. The questionnaire comprises three subscales: emotional eating (13 items;

7 e.g., "Do you have a desire to eat when you are irritated?"), external eating (10 items; e.g., "If

8 food smells and looks good, do you eat more than usual?"), and restrained eating (10 items;

9 e.g., "Do you try to eat less at mealtimes than you would like to eat?"). The Likert scale 10 responses range from 1 (Never) to 6 (Very often). Second-order CFA provided support for a 11 single-factor model on the eating behaviours $\left(\chi^{2}=1130.77 ; N=171\right.$; $\mathrm{df}=397, \mathrm{CFI}=.91$; $12 \mathrm{TLI}=.90 ; \mathrm{RMSEA}=.061 ;$ RMSEA 90\% CI $=.051-.075)$. In this study, we reversed all 13 scores to consider a low score as an unhealthy eating behaviour and a high score as a healthy 14 eating behaviour.

Susceptibility to doping. The measure used in the present study was based on both the 16 series of scenarios developed by Zelli, Mallia, and Lucidi (2010) and the items used to 17 measure doping intention in past research (Barkoukis et al., 2013; Lazuras et al., 2010). The 18 participating adolescents and young adults read five hypothetical scenarios concerning the 19 susceptibility to doping. In particular, they were asked to imagine being the protagonist in 20 interpersonal situations in which someone else offered or advised them to use performance21 enhancing substances. The scenarios presented situations occurring in ecologically valid 22 contexts, such as in a gym or on a sport team. The formulation of the scenarios was adapted 23 to the gender of the participants. For example, a typical scenario presented to male athletes 24 was as follows: 
24 alone.

\section{Results}

"You are a member of a team that trains several times a week. One day at the end of training, one of your teammates pulls you aside and tells you about using a substance that, in a very short time, made him stronger and more resistant to fatigue. He confesses that he has been able to improve his game performance using this product. He then asks you to follow him and offers you a sample, recommending that you use it in the coming days and reassuring you that it will work on you as well."

After reading each scenario, the participants were asked to answer the question: If you were in this situation, would you do what was suggested? on a Likert scale from 1 (Not at all likely) to 6 (Totally likely) about the susceptibility to doping.

\section{Data analyses}

Accordng to GPower (Erdfelder, Faul, \& Buchner, 1996), the total required sample size for detecting large effect sizes with an alpha level of 5\% was 44 . All analyses were conducted using SPSS version 22.0 for Windows. We performed a mediation analysis for each independent variable (i.e., intrinsic motivation, external motivation regulation, introjected regulation, and identified regulation in sport) following the bootstrap procedure outlined by Preacher and Hayes (2008) and using the INDIRECT macro in SPSS. The bootstrap procedure resampled the data 5000 times and calculated the indirect effect for each sample. The bias-corrected $95 \%$ confidence interval of the indirect effects was obtained for the 5000 bootstrap resamples. The bias-corrected $95 \%$ confidence interval indicates significant indirect effects if it does not contain zero (Preacher \& Hayes, 2008). For all mediation analyses, we also computed $R^{2}$ to quantify the proportion of variance explained in the outcome that could be attributed to both the predictor and the mediator but to neither 
1 Means, standard deviations, coefficient alphas, and bivariate correlations for all

2 variables are presented in Table 1. Results indicated that all forms of motivation were

3 moderately related to susceptibility to doping in the expected directions. In addition, while

4 intrinsic motivation was weakly and positively related to healthy eating behaviour, converse

5 and small relations were found with external and introjected motivation. Healthy eating

6 behaviours were highly and negatively related to susceptibility to doping.

For each of the four models, we tested the mediating role of eating behaviours in the

8 relationship between motivation and susceptibility to doping. The four mediation models

9 examined the four forms of motivation as independent variables. Each mediation model was

10 significant. We present the details of each of the mediation pathways across each model in

11 Table 2. In summary, intrinsic motivation and the most intrinsic form of extrinsic motivation

12 (extrinsic motivation with identified regulation) were negatively related to susceptibility to

13 doping through healthy eating behaviours $\left(\mathrm{c}_{1}{ }^{\prime}=-.16^{*} ; \mathrm{c}_{2}{ }^{\prime}=-.14^{*}\right)$, whereas the clear

14 extrinsic forms of extrinsic motivation (with introjected regulation and with external

15 regulation) were positively related to susceptibility to doping through healthy eating

16 behaviours $\left(\mathrm{c}_{3}{ }^{\prime}=.25^{*} ; \mathrm{c}_{4}{ }^{\prime}=.34 *\right)$. The models explained between $19.29 \%$ and $22.31 \%$ of the

17 variance in susceptibility to doping (see Table 2).

\section{Discussion}

19 In the present study, we investigated the mediating role of eating behaviours in the

20 relationship between motivation and the susceptibility to doping in sport. Although the

21 effects were small to moderate, there was a consistent mediating effect for each of the four

22 degrees of self-determined motivation. This is the first study to investigate the possible role

23 of eating behaviours in this motivational context of doping.

24 The most self-determined forms of motivation (i.e., intrinsic motivation and extrinsic

25 motivation with identified regulation) were positively related to eating behaviours, which in 
1 turn suggested a protective role against the susceptibility to doping (see also Hagger et al.,

2 2006; Mata et al., 2009). Conversely, the most externally regulated forms of motivation (i.e.,

3 extrinsic motivation with introjected and external regulation) were negatively related to

4 eating behaviours, which is consistent with previous studies (Chan et al., 2018b). The

5 findings enrich our theoretical understanding of how the SDT approach to motivation for

6 sport in related to doping. The relationships that have been demonstrated here provide both a

7 more complete picture of athletes' doping susceptibility and an initial evidenced-based

8 explanation of how the mediation of eating behaviours may at least partially account for it.

The results showed direct relationships between the motivation for sport and doping

10 susceptibility variables, which confirmed our expectations and previous studies. Indeed,

11 intrinsic and identified regulations of motivation were negatively related to the susceptibility

12 to doping, whereas introjected and external regulations were positively related. These results

13 are in line with the SDT tenet that self-determined motivation entails more adaptive patterns

14 in terms of cognitive, affective and behavioural consequences (Deci \& Ryan, 1985, 2000).

15 Our findings are consistent with the results of previous doping-related work, notably the

16 results showing that intrinsically motivated athletes had the lowest scores for doping

17 substance use and that athletes with less controlled motivation showed higher adaptive

18 behaviours (Chan et al., 2018b).

19 In agreement with the literature suggesting that self-determined individuals are less apt 20 to develop eating disorders because they better self-regulate their behaviour (e.g., Kopp \& 21 Zimmer-Gembeck, 2011; Mask \& Blanchard, 2011; Pelletier, Dion, \& Lévesque, 2007), we 22 observed that both intrinsic motivation and identified regulation of motivation for sport were 23 positively related to healthy eating behaviours. In contrast, both introjected and external 24 regulations of motivation for sport were negatively related to healthy eating behaviours.

25 These results are consistent with earlier studies demonstrating positive relationships between 
1 self-determined motivation and improvement in eating self-regulation and healthy body

2 weight maintenance (e.g., Hagger et al., 2006; Mata et al., 2009). They further indicate that

3 self-determination theory is a fruitful framework for examining the processes of regulating

4 eating behaviours.

5 Given that disordered eating and supplement use have been shown to be related to

6 doping susceptibility and eating behaviour, we proposed that eating behaviour might be

7 associated with the susceptibility to doping in athletes (e.g., Barkoukis et al., 2015;

8 Kiezebrink et al., 2009; van Strien, Engels, van Leeuwe, \& Snoek, 2005). Interestingly, the

9 relationship between eating behaviour and the susceptibility to doping was stronger than the

10 relationship between the different forms of motivation and doping. Eating behaviour thus

11 may be a central factor in the relationship that might be considered as underpinning the

12 susceptibility to doping. This finding was in accordance with our expectations and with a

13 study suggesting that unhealthy eating behaviours are associated with doping susceptibility in

14 high-level athletes (Rousselet et al., 2017). It also supports the notion that knowledge about

15 nutrition (which may contribute to eating habits) can be a protective factor against doping

16 susceptibility (Kondric et al., 2013). The relationship also extends the conclusions of

17 previous meta-analyses that have evidenced the comorbidity of substance use disorders

18 among individuals with eating disorders (e.g., Bahji et al., 2019) or reported that supplement

19 use might be a pathway towards doping susceptibility in athletes (Ntoumanis et al., 2014).

20 The main research question of the present study concerned the mediating role of eating

21 behaviours in the relationships between motivation for sport and susceptibility to doping. Our

22 study corroborates previous research showing that self-determination theory is applicable to

23 healthy or unhealthy eating behaviours and susceptibility to doping (Barkoukis et al., 2011;

24 Chan et al., 2015; Kopp \& Zimmer-Gembeck, 2011; Mask \& Blanchard, 2011). The pattern

25 of effects provided evidence that controlled motivation for sport (i.e., introjected and external 
1 regulation) was related to susceptibility to doping through the salient variable related to

2 unhealthy eating behaviours. Conversely, autonomous forms of motivation for sport (i.e.,

3 intrinsic and identified regulation) were negatively related to doping susceptibility through

4 the mediating role of eating behaviours. These relationships suggested a complex

5 motivational dynamic underlies susceptibility to doping among athletes. They also suggest

6 that the self-determination of athletes is associated with a lower susceptibility of doping due

7 to a greater ability to control their eating behaviours, whereas athletes who are extrinsically

8 motivated might be susceptible to doping, likely because of a lack of eating behaviour 9 control.

Given the relationship between eating behaviours and doping, researchers would do 11 well to investigate in greater depth the underlying common features of eating behaviours and 12 the propensity to doping. For example, neuroticism and impulsivity (Garcia-Argibay, 2019) 13 and low self-control (Kabiri, Shadmanfaat, \& Donner, 2019) could be examined in 14 relationship with both behaviours (i.e., eating behaviours and doping propensity) 15 concomitantly.

\section{$17 \quad$ Limitations and perspectives}

18 This study has some limitations. First, we used the BREQ-2 to measure motivation for 19 sport, although this questionnaire was designed to measure motivation for exercise rather 20 than sport. It should be noted here that the integrated regulation subscale, which reflects 21 personal endorsed values, goals and needs, has recently been validated in the Portuguese 22 version of the BREQ-2 (Cid et al., 2018) but not yet in the French version. Future studies 23 should therefore use a scale specifically designed to measure motivation for sport (Pelletier et 24 al., 1995) and include the assessment of integrated regulation, as this would ensure the 25 complete analysis of the behavioural regulations proposed by the SDT framework. 
A second limitation is the cross-sectional design, which limits any conclusions that one

2 might draw about the relationships between motivation, eating behaviours and susceptibility

3 to doping. Future studies should thus use prospective research designs in order to further test

4 this indirect model and to test the temporal sequence of the model. For example, longitudinal

5 or intervention and experimental designs that involve manipulating support to promote

6 autonomous motivation (e.g., Chatzisarantis \& Hagger, 2009) might provide data that

7 confirm the direction of the effects proposed by SDT and the mediation models tested here.

8 Also, athletes in different sports do not all display the same eating behaviours (Sherman \&

9 Thompson, 2009), nor do they have the same approach to doping susceptibility (Alaranta et

10 al., 2006). Indeed, the risk of doping appears to be highest in speed and power sports and

11 lowest in sports that demand high motor skills (Alaranta et al., 2006). This limitation suggests

12 the need to examine the differences between these types of sport with regard to the

13 relationships between motivation, eating behaviours and susceptibility to doping.

14 Third, self-report measures and vignettes to assess susceptibility to doping are not

15 proxies for real-life doping behaviour and may thus have been subject to social desirability

16 bias. Although we have no specific evidence of this bias, the use of implicit measures of

17 eating behaviours (e.g., Smith, Forrest, Velkoff, Ribeiro, \& Franklin, 2018) would help to

18 overcome any potential reporting bias in future studies. Also, future research on susceptibility

19 to doping could include an implicit-association test (e.g., Chan et al., 2018a).

20 Notwithstanding this limitation, it is difficult to see how such biases could have yielded the

21 specific pattern of results and relationships that emerged in this study.

$22 \quad$ What does this article add?

23 This study examined the associations between self-determination theory constructs and

24 doping susceptibility in sport through the mediating perspective of eating behaviours. The

25 results revealed that the relationships between the different degrees of motivational regulation 
1 for sport (i.e., intrinsic, identified, introjected and external) and the susceptibility to doping

2 were each mediated by eating behaviours. These results suggest that when athletes are

3 intrinsically motivated, they are more prone to regulate their eating behaviours. These

4 motivational strategies and behaviours might be associated with a lower proneness to doping.

5 Conversely, when athletes are extrinsically motivated, they are less prone to regulate their

6 eating behaviours. These motivational strategies and behaviours are associated with a greater

7 proneness to doping. Finally, the central position of eating behaviours in the relationship

8 between motivation and doping susceptibility opens up a potential line of research that places

9 eating behaviours at the forefront of future research on the psychology of doping. To

10 conclude, self-determination theory offers a relevant framework for investigating the

11 motivational correlates of susceptibility to doping, and eating behaviours seem to be central

12 in that process. 
1 Acknowledgments

2 The authors are grateful to the athletes for their participation. Thanks for Alexandre Vidal for 3 his help in the collection of the data. 
MOTIVATION, EATING BEHAVIOUR, AND DOPING

1 Endnote

2 The sample of the present study is derived from a larger-scale project funded by WADA's

3 Social Science Research Grant Program.

4

5 
MOTIVATION, EATING BEHAVIOUR, AND DOPING

\section{References}

2 Alaranta, A., Alaranta, H., Holmila, J., Palmu, P., Pietilä, K., \& Helenius, I. J. (2006). Selfreported attitudes of elite athletes towards doping: Differences between type of sport. International Journal of Sports Medicine, 27, 842-846.

Bahji, A., Mazhar, M. N., Hawken, E., Hudson, C. C., Nadkarni, P., \& MacNeil, B. A. (2019). Prevalence of substance use disorder comorbidity among individuals with eating disorders: A systematic review and meta-analysis. Psychiatry Research, 273, $58-66$

Bailly, N., Maitre, I., Amanda, M., Hervé, C., \& Alaphilippe, D. (2012). The Dutch Eating Behaviour Questionnaire (DEBQ). Assessment of eating behaviour in an aging French population. Appetite, 59, 853-858.

Barkoukis, V., Lazuras, L., Lucidi, F., \& Tsorbatzoudis, H. (2015). Nutritional supplement and doping use in sport: Possible underlying social cognitive processes. Scandinavian Journal of Medicine and Science in Sports, 25, 582-588.

Barkoukis, V., Lazuras, L., Tsorbatzoudis, H., \& Rodafinos, A. (2011). Motivational and sportspersonship profiles of elite athletes in relation to doping behaviour. Psychology of Sport and Exercise, 12, 205-212.

Barkoukis, V., Lazuras, L., Tsorbatzoudis, H., \& Rodafinos, A. (2013). Motivational and social cognitive predictors of doping intentions in elite sports: An integrated approach. Scandinavian Journal of Medicine and Science in Sports, 23, 330-340.

Cebolla, A., Barrada, J. R., Van Strien, T., Oliver, E., \& Baños, R. (2014). Validation of the Dutch Eating Behavior Questionnaire (DEBQ) in a sample of Spanish women. Appetite, 73, 58-64.

Chan, D. K. C., Dimmock, J. A., Donovan, R., Hardcastle, S., Lentillon-Kaestner, V., \& Hagger, M. (2015). Self-determined motivation for sport predicts anti-doping 
MOTIVATION, EATING BEHAVIOUR, AND DOPING

1

2

3

4

5

6

7

8

9

10

11

motivation and intention: A perspective from the trans-contextual model. Journal of Science and Medicine in Sport, 18, 315-322.

Chan, D. K. C., Keatley, D. A., Tang, T. C., Dimmock, J. A., \& Hagger, M. S. (2018a). Implicit versus explicit attitude to doping: Which better predicts athletes' vigilance towards unintentional doping?. Journal of Science and Medicine in Sport, 21, 238244.

Chan, D. K. C., Tang, T. C., Gucciardi, D. F., Ntoumanis, N., Dimmock, J. A., Donovan, R. J., ... \& Hagger, M. S. (2018b). Psychological and behavioural factors of unintentional doping: A preliminary systematic review. International Journal of Sport and Exercise Psychology.

Chatzisarantis, N. L. D., \& Hagger, M., (2009). Effects of an intervention based on selfdetermination theory on self-reported leisure-time physical activity participation. Psychology and Health, 24, 29-48.

Cid, L., Monteiro, D., Teixeira, D., Alves, S., Moutão, J., Teques, P., ... \& Palmeira, A. (2018). The behavioural regulation in exercise questionnaire (BREQ-3) Portugueseversion: evidence of reliability, validity and invariance across gender. Frontiers in Psychology, 9, 1940.

Corrion, K., Scoffier-Mériaux, S., \& d'Arripe-Longueville, F. (2017). Self-regulatory mechanisms of doping intentions in elite athletes: The role of self-determined motivation in sport. Journal of Sports Medicine \& Doping Studies, 7, 197.

Deci, E. L., \& Ryan, R. M. (1985). Intrinsic motivation and self-determination in human behaviour. New York: Plenum.

Deci, E. L., \& Ryan, R. M. (1991). A motivational approach to self: Integration in personality. In R. Dienstbier (Ed.), Nebraska symposium on motivation: Vol. 38, Perspectives on motivation (pp. 237-288). Lincoln: University of Nebraska Press. 
1 Deci, E. L., \& Ryan, R. M. (2000). The" what" and" why" of goal pursuits: Human needs and the self-determination of behaviour. Psychological Inquiry, 11, 227-268.

3 Erdfelder, E., Faul, F., \& Buchner, A. (1996). GPOWER: A general power analysis program. Behavior Research Methods, Instruments, \& Computers, 28(1), 1-11. Psychology, 37(4), 924-933. Psychological Science, 18, 233-239.

9 Garcia-Argibay, M. (2019). The relationship between the Big Five personality traits, impulsivity, and anabolic steroid use. Substance Use \& Misuse, 54(2), 236-246.

11 Hagger, M. S., Chatzisarantis, N. L., \& Harris, J. (2006). From psychological need satisfaction to intentional behaviour: Testing a motivational sequence in two behavioural contexts. Personality and Social Psychology Bulletin, 32, 131-148.

14 Hagger, M. S., Hardcastle, S. J., Chater, A., Mallett, C., Pal, S., \& Chatzisarantis, N. L. (2014). Autonomous and controlled motivational regulations for multiple healthrelated behaviours: between-and within-participants analyses. Health Psychology and

21 Hu, L., \& Bentler, P. M. (1999). Cutoff criteria for fit indexes in covariance structure Behavioural Medicine: An Open Access Journal, 2, 565-601.

Hodge, K., Hargreaves, E. A., Gerrard, D. F., \& Lonsdale, C. (2013). Psychological mechanisms underlying doping attitudes in sport: Motivation and moral disengagement. Journal of Sport and Exercise Psychology, 35, 419-432. analysis: Conventional criteria versus new alternatives. Structural Equation Modeling: A Multidisciplinary Journal, 6, 1-55. 
MOTIVATION, EATING BEHAVIOUR, AND DOPING

1 Kabiri, S., Shadmanfaat, S. M., \& Donner, C. M. (2019). Using control balance theory to

2

3

4

5

6

7

8

9

10

11 examine sports doping among professional athletes in Iran. Journal of Drug Issues, 49(3), 493-511.

Kiezebrink, K., Campbell, D., Mann, E., \& Blundell, J. (2009). Similarities and differences between excessive exercising anorexia nervosa patients compared with DSM-IV defined anorexia nervosa subtypes. Eating and Weight Disorders-Studies on Anorexia, Bulimia and Obesity, 14, e199-e204.

Kondric, M., Sekulic, D., Uljevic, O., Gabrilo, G., \& Zvan, M. (2013). Sport nutrition and doping in tennis: An analysis of athletes' attitudes and knowledge. Journal of Sports Science and Medicine, 12, 290.

Kopp, L. K., \& Zimmer-Gembeck, M. J. (2011). Resisting the thin ideal and access to autonomy support: Women's global self-determination, body dissatisfaction and eating. Eating Behaviours, 2, 222-224.

Lazuras, L., Barkoukis, V., Rodafinos, A., \& Tsorbatzoudis, H. (2010). Predictors of doping intentions in elite-level athletes: A social cognition approach. Journal of Sport and Exercise Psychology, 32(5), 694.

Markland, D., \& Tobin, V. (2004). A modification to the behavioural regulation in exercise questionnaire to include an assessment of amotivation. Journal of Sport \& Exercise Psychology, 26, 191-196.

Mata, J., Silva, M. N., Vieira, P., Carraça, P. E., Andrade, A. M., Coutinho, S., ..., Teixeira, P. (2009). Motivational "spill-over" during weight control: Increased selfdetermination and exercise intrinsic motivation predict eating self-regulation. Health Psychology, 28, 709-716. 
1 Mask, L., \& Blanchard, C. M. (2011). The effects of "thin ideal" media on women's body image concerns and eating-related intentions: The beneficial role of an autonomous regulation of eating behaviors. Body Image, 8, 357-365.

Ntoumanis, N., Ng, J. Y., Barkoukis, V., \& Backhouse, S. (2014). Personal and psychosocial predictors of doping use in physical activity settings: A meta-analysis. Sports Medicine, 44, 1603-1624. canadienne des sciences du comportement, 27(2), 140.

11 Pelletier, L. G., Dion, S., \& Lévesque, C. (2004). Can self-determination help protect women against sociocultural influences about body image and reduce their risk of experiencing bulimic symptoms. Journal of Social and Clinical Psychology, 23(1), $61-88$

Petróczi, A. (2007). Attitudes and doping: a structural equation analysis of the relationship between athletes' attitudes, sport orientation and doping behaviour. Substance Abuse Treatment, Prevention, and Policy, 2, 34.

Petróczi, A., \& Aidman, E. (2009). Measuring explicit attitude toward doping: Review of the psychometric properties of the Performance Enhancement Attitude Scale. Psychology of Sport and Exercise, 10, 390-396.

21 Preacher, K. J., \& Hayes, A. F. (2008). Asymptotic and resampling strategies for assessing and comparing indirect effects in multiple mediator models. Behaviour Research Methods, 40, 879-891.

24 Rousselet, M., Guérineau, B., Paruit, M. C., Guinot, M., Lise, S., Destrube, B., ..., Prétagut, 25 S. (2017). Disordered eating in French high-level athletes: Association with type of 
MOTIVATION, EATING BEHAVIOUR, AND DOPING

1 sport, doping behaviour, and psychological features. Eating and Weight DisordersStudies on Anorexia, Bulimia and Obesity, 22, 61-68.

3 Ryan, R. M., \& Deci, E. L. (2000). Self-determination theory and the facilitation of intrinsic motivation, social development, and well-being. American Psychologist, 55(1), 68.

Ryan, R. M., \& Deci, E. L. (2008). A self-determination theory approach to psychotherapy:

6

7

8 The motivational basis for effective change. Canadian Psychology/Psychologie Canadienne, 49, 186.

Sherman, R. T., \& Thompson, R. A. (2009). Body image and eating disturbance in athletes: Competing to win or to be thin? In: Justine J. Reels, Katherine A. Beals (Eds). The Hidden Faces of Eating Disorders and Body Image (pp. 9-38). Reston, VA: AAHPERD.

Smith, A. R., Forrest, L. N., Velkoff, E. A., Ribeiro, J. D., \& Franklin, J. (2018). Implicit attitudes toward eating stimuli differentiate eating disorder and non-eating disorder groups and predict eating disorder behaviours. International Journal of Eating Disorders, 51, 343-351.

Van Strien, T. (2002). Dutch Eating Behaviour Questionnaire: Manual. London: Pearson.

Van Strien, T., Engels, R. C., Van Leeuwe, J., \& Snoek, H. M. (2005). The Stice model of overeating: Tests in clinical and non-clinical samples. Appetite, 45, 205-213.

Zelli, A., Mallia, L., \& Lucidi, F. (2010). The contribution of interpersonal appraisals to a social-cognitive analysis of adolescents' doping use. Psychology of Sport and Exercise, 11, 304-311. 
MOTIVATION EATING BEHAVIOUR DOPING INTENTION

1 Table 1. Descriptive statistics, reliability coefficients, and Pearson correlations $(N=171)$.

(1)

(2)

(3)

(4)

(5)

(6)

\begin{tabular}{lrrrrrr}
\hline Mean & 5.33 & 4.91 & 2.76 & 2.39 & 2.27 & 2.02 \\
Standard deviation & .64 & .97 & 1.07 & .71 & .58 & 1.41 \\
$\begin{array}{l}\text { (1) Intrinsic } \\
\text { motivation }\end{array}$ & .74 & .02 & -.02 & $.12^{*}$ & $.12^{*}$ & $-.13^{*}$
\end{tabular}

(2) Extrinsic

motivation with

.77

$.40^{* *}$

.09

$.21^{* *}$

$-.25^{*}$

identified regulation

(3) Extrinsic

motivation with

introjected

.73

$.35^{* *} \quad-.30^{* *}$

$.23^{* *}$

regulation

(4) Extrinsic

motivation with

.76

$-.21^{* *}$

$.25^{* *}$

external regulation

(5) Healthy eating

behaviours

.84

$-.45^{* *}$

(6) Susceptibility to

doping use

2 Notes. ${ }^{*} p \leq .05,{ }^{*} p \leq .01$. The Cronbach alpha values are reported on the diagonal.

3

4

5 
1 Table 2. Summary of bootstrap mediation analyses.

\begin{tabular}{|c|c|c|c|c|c|c|c|c|c|c|}
\hline $\begin{array}{l}\text { Independent } \\
\text { variable }\end{array}$ & $\begin{array}{c}\text { Mediator } \\
\text { variable }\end{array}$ & $\begin{array}{l}\text { Dependent } \\
\text { variable }\end{array}$ & $\begin{array}{l}a \text { path } \\
\text { coef }\end{array}$ & $b$ path coef & $c$ path coef & $c^{\prime}$ path coef & $\begin{array}{c}\text { Mean } \\
\text { indirect } \\
\text { effect }\end{array}$ & $\begin{array}{l}\text { SE of } \\
\text { mean }\end{array}$ & $\begin{array}{c}\text { Bias-corrected } \\
\text { 95\% CI mean } \\
\text { effect }\end{array}$ & $R^{2}$ \\
\hline $\begin{array}{l}\text { Intrinsic } \\
\text { motivation }\end{array}$ & $\begin{array}{c}\text { Eating } \\
\text { behaviours }\end{array}$ & $\begin{array}{l}\text { Susceptibility to } \\
\text { doping use }\end{array}$ & $.18^{*}$ & $-1.02 *$ & $-.32 *$ & $-.16^{*}$ & -.18 & .06 & {$[-.33,-.06]$} & $19.29 \%$ \\
\hline $\begin{array}{c}\text { Extrinsic } \\
\text { motivation with } \\
\text { identified } \\
\text { regulation }\end{array}$ & $\begin{array}{c}\text { Eating } \\
\text { behaviours }\end{array}$ & $\begin{array}{l}\text { Susceptibility to } \\
\text { doping use }\end{array}$ & $.11^{*}$ & $-1.50 *$ & $-.32 *$ & $-.14^{*}$ & -.17 & .05 & {$[-.30,-.09]$} & $19.67 \%$ \\
\hline $\begin{array}{c}\text { Extrinsic } \\
\text { motivation with } \\
\text { introjected } \\
\text { regulation }\end{array}$ & $\begin{array}{c}\text { Eating } \\
\text { behaviours }\end{array}$ & $\begin{array}{l}\text { Susceptibility to } \\
\text { doping use }\end{array}$ & $-.09 *$ & $-1.49^{*}$ & $.39 *$ & $.25 *$ & -.13 & .06 & {$[-.27,-.02]$} & $19.37 \%$ \\
\hline $\begin{array}{c}\text { Extrinsic } \\
\text { motivation with } \\
\text { external } \\
\text { regulation }\end{array}$ & $\begin{array}{c}\text { Eating } \\
\text { behaviours }\end{array}$ & $\begin{array}{l}\text { Susceptibility to } \\
\text { doping use }\end{array}$ & $-.12 *$ & $-1.49^{*}$ & $.52 *$ & $.34 *$ & -.18 & .07 & {$[-.35,-.07]$} & $22.31 \%$ \\
\hline
\end{tabular}




\section{MOTIVATION EATING BEHAVIOUR DOPING INTENTION}

1 Notes. SE: standard error; CI: confidence interval; ${ }^{*} p<.05$. $a$-path: relationship between the Independent variable and the Mediator variable; $b$ -

2 path: relationship between the Mediator variable and the Dependent variable. c-path: relationship between the Independent variable and the

3 Dependent variable; $c^{\prime}$-path: relationship between the Independent variable and the Dependent variable controlling for the Mediator variable. 4

5

6 
1 Figure 1. Hypothetical mediation models of the relationship between SDT motivational

2 constructs, eating behaviours and susceptibility to doping use.

3
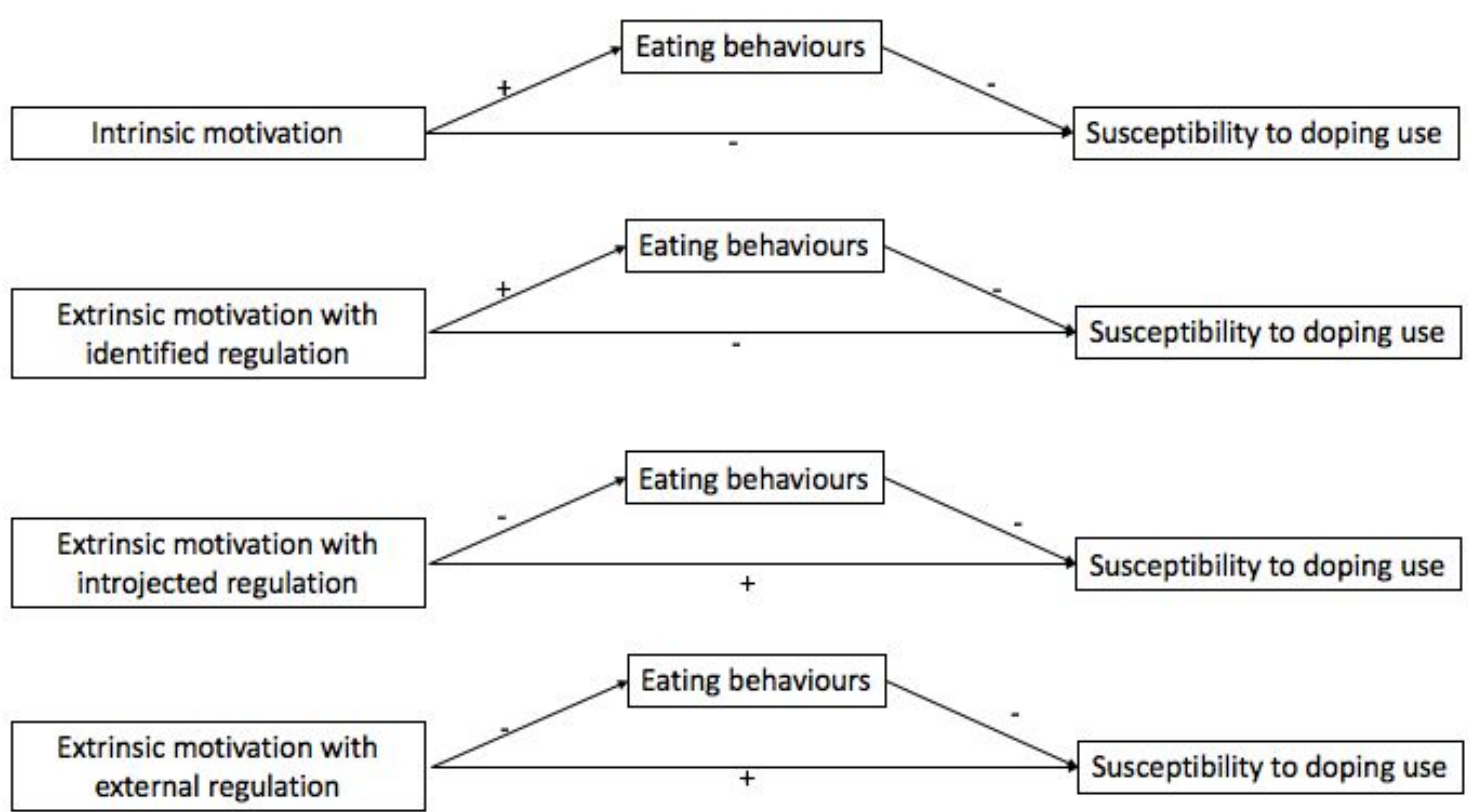

4

5

6

7 